\title{
Do Mobile Phones Cause More Harm than Good?
}

\author{
Rohan Mani \\ McLean High School, McLean, VA, USA \\ Email: rohanmani@msn.com
}

How to cite this paper: Mani, R. (2019) Do Mobile Phones Cause More Harm than Good? Open Journal of Social Sciences, 7, 198-205.

https://doi.org/10.4236/jss.2019.78014

Received: July 19, 2019

Accepted: August 17, 2019

Published: August 20, 2019

Copyright $\odot 2019$ by author(s) and Scientific Research Publishing Inc. This work is licensed under the Creative Commons Attribution International License (CC BY 4.0).

http://creativecommons.org/licenses/by/4.0/ (c) (i) Open Access

\begin{abstract}
Mobile phones have significantly transformed our lives over the past decade. There is even evidence to suggest that mobile phones have revolutionized the lives of millions of people in poverty by increasing their access to education, weather information (particularly important for farmers and fishermen) and critical knowledge pertaining to business and healthcare from even remotest locations. While mobile phones are transforming societies and economies for the better, little is known about their harmful effects on people and the planet. There is a growing research area that is now looking at the Life Cycle Assessment (LCA) of mobile phone technology, that involves risks to health of the workers engaged in extracting the raw materials (metals and solvents) used in the manufacture of mobile phones, health risks to workers during production of the various components (plastics and heavy metals), risks to consumers, and risk to the ecosystem when the phones are thrown away in a landfill or burned in an incinerator. This paper makes a contribution in this area by bringing together existing evidence on how mobile phone usage is associated with significant health risks. This ranges from radiation exposure to sleep disorder to withdrawal and depression at the other extreme especially among youth. Also, damning evidence linking road accidents and mobile phone usage can no longer be ignored. This paper delves into this emerging literature while providing possible solutions on how we can manage and mitigate this growing challenge.
\end{abstract}

\section{Keywords}

Mobile Phones, Hazardous, Harmful Health Effects, Life Cycle Assessment, Heavy Metals

\section{Introduction}

\subsection{How Mobile Phones Have Transformed Our Lives}

Mobile phones have significantly transformed our lives over the past decade and 
have become indispensable part of our lives. They have not only allowed for people all around the world to connect with ease but have also been adopted for different purposes such as conducting business, entertainment and for providing emergency alerts. Nowadays, we are always mere seconds away from learning about happenings around the world.

There is even evidence to suggest that mobile phones have revolutionized the lives of millions of people in poverty by increasing their access to education, weather information (particularly important for farmers and fishermen) and critical knowledge pertaining to business and healthcare from even remotest locations [1]. There are currently over 5 billion mobile users worldwide and that number is only continuing to grow. With increases in speed and other technological breakthroughs, mobile phones now serve as keys to the world for much of the global population.

\subsection{But, Mobile Phones Can Cause Significant Harm}

While there is evidence demonstrating the extent to which mobile phone are transforming societies and economies for the better, little is known about their harmful effects on people and the planet. Mobile phone usage has also now been increasingly associated with significant health risks. There is some emerging evidence linking mobile phones and the devastating health and environmental impacts of mobile phone manufacturing and disposal in addition to cognitive impairment from excessive mobile phone usage. There are also now definitive statistics linking mobile phone usage with traffic accidents. The objective of this paper is to examine some of the harmful effects that come with the use and abuse of mobile phone technology and to outline possible solutions to manage and mitigate this growing challenge.

\section{Life Cycle Assessment of Mobile Phones}

There is a growing research area that is now looking at the Life Cycle Assessment (LCA) of mobile phone technology (Figure 1), that involves risks to health

Lifecycle of a Mobile Phone

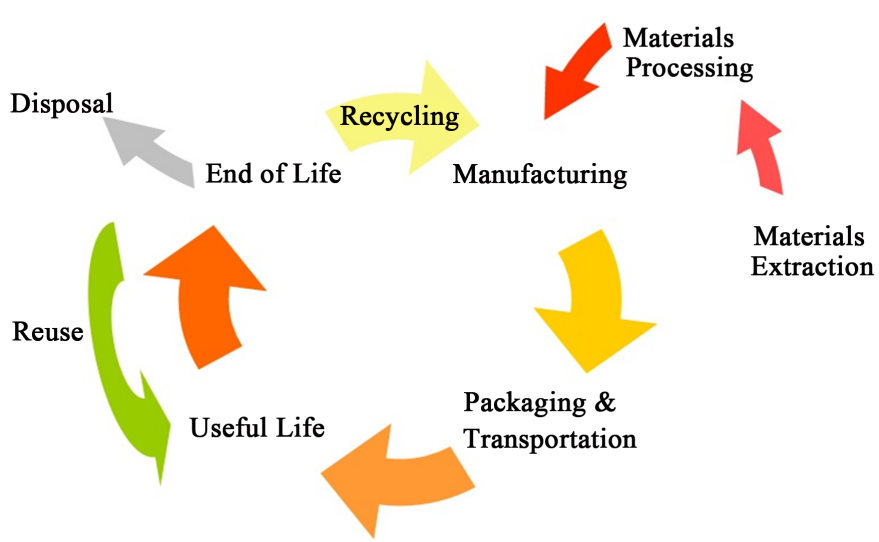

Figure 1. Lifecycle of a mobile phone. 
of the workers engaged in extracting the raw materials (metals and solvents) used in the manufacture of mobile phones, health risks to workers during production of the various components (plastics and heavy metals), risks to consumers, and risk to the ecosystem when the phones are thrown away in a landfill or burned in an incinerator [2].

\subsection{Mobile Phone Manufacturing}

Most mobile phones contain precious metals and plastics and when placed in a landfill, these materials can pollute the air and contaminate soil and drinking water. Heavy metals such as cadmium, lead, lithium, and mercury are some of the many materials used in the manufacturing of mobile phones (Figure 2). A ton of used mobile phones for example contain about $3.5 \mathrm{~kg}$ of silver, 340 grams of gold, 140 grams of palladium, and 130 grams of copper and an average mobile phone battery contains another 3.5 grams of copper [3]. Coincidentally, an unusually high incidence of leukemia, lymphoma, brain cancer, and other serious diseases appears to exist among relatively young people who have worked in the factories that manufacture mobile phones [4]. Similarly, chemical slurries created in the process of extracting these raw materials contaminate groundwater creating severe environmental hazards.

\section{Recipe for danger: What's inside your mobile?}

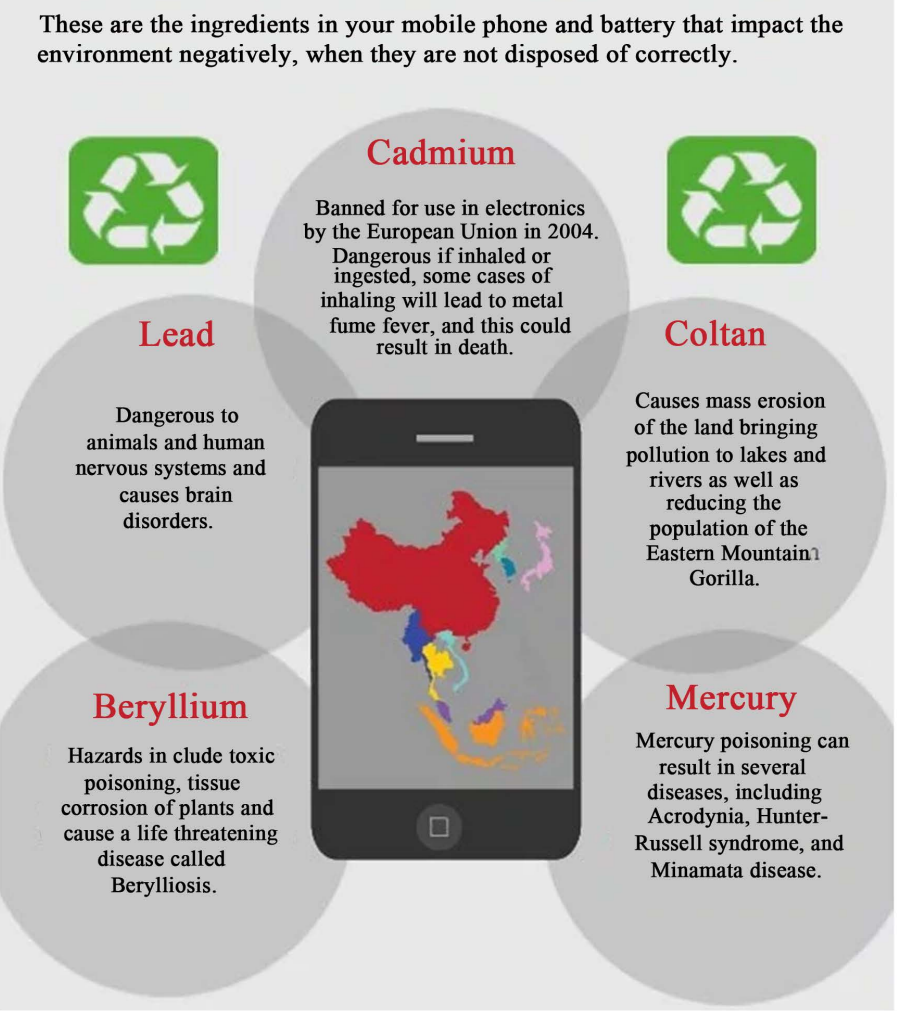

Figure 2. Chemical substances in mobile phones. Source: Nokia (2014).

https://technologicalresponsibilities.wordpress.com/2014/07/18/eco-friendly-phone-by-n okia/ 


\subsection{Mobile Phone Disposal}

Millions of mobile phones are discarded each year. The improper disposal of mobile phones can cause significant adverse health effects and environmental degradation. The materials found in mobile phones are highly toxic substances, and their improper disposal can often lead to soil and water contamination causing harm to both flora and fauna [5]. Mercury in water can cause very significant health damage, and lithium and lead can similarly contaminate soil and water that plants and animals need to survive. Lead exposure can cause damage to the reproductive, blood and nervous systems and mercury exposure contributes to brain and kidney damage. Similarly, low levels of exposure to Arsenic can cause negative impacts on skin, liver, nervous and respiratory systems and cadmium is often associated with deficits in cognition, learning, behavior and neuromotor skills in children in addition to kidney damage [6]. Finally, the health risks are often borne by the very poor people who deal with electronic waste exported from the rich countries to poor ones in west Africa, southeast Asia, India, etc.

\subsection{Mobile Phone Usage}

Mobile phone usage has also now been associated with significant health risks. Exposure to the radiofrequency (RF) fields emitted by mobile phones is generally found to be 1000 times more significant than that of mobile phone towers themselves. Although presently inconclusive, there is ongoing research exploring potential links to brain tumors, cancer, and other detrimental health effects associated with frequent mobile phone usage [7]. In one type of study, called a case-control study, mobile phone use has been compared between people with and without brain tumors. In another type of study, called a cohort study, large groups of people who had not had cancer were followed over time and the incident rate of brain tumors in people with and without mobile phones was compared. Although these studies have so far not shown clear evidence of a relationship between mobile phone use and cancer, researchers have reported some statistically significant associations for certain subgroups of people [8].

The International Agency for Research on Cancer has now classified mobile phone radiation as possibly carcinogenic. Children have the potential to be at greater risk than adults for developing brain cancer from cell phones. This is primarily because their heads are smaller than those of adults and proportionately, have a greater chance of exposure to the radiofrequency radiation that is emitted by cell phones. Additionally, children on average accumulate significantly more years of cell phone exposure than do adults. While the research is still evolving, data from studies in children with cancer do not yet support this theory [9].

Scientists have also reported other adverse health effects stemming from usage 
of mobile phones including changes in brain activity, reaction times, and sleep patterns. Other neurological symptoms could include depression, sadness, headaches, and sleep deprivation primarily amongst youth. Positive associations have also been found between relatively high mobile phone usage and current stress, sleep disturbance, and symptoms of depression for both men and women, after adjusting for relationship status, educational level, and present occupation. This evolving research area is, therefore, indicative that high frequencies of mobile phone use could be a potential risk factor for developing sleep disturbance, stress and symptoms of depression in both the men and women [10]. Similarly, results also show improved mental health in people with lower rates of mobile phone usage [11].

\section{Mobile Phone Usage and Traffic Accidents}

There is also mounting evidence that suggests a link between mobile usage and an increased risk of traffic accidents. Studies now suggest that there is a $3-4$ times greater chance of an accident, when mobile phones are used while driving (due to distraction).The National Safety Council reports that mobile phone use while driving leads to 1.6 million crashes each year. Nearly 390,000 injuries occur each year from accidents caused by texting while driving and 1 out of every 4 car accidents in the United States is caused by texting and driving. Recent data collected by Cambridge Mobile Telematics from hundreds of thousands of drivers appears to strengthen the view that mobile phones have made American highways far more dangerous. The data also suggests that none of the laws that have been enacted so far have made so much as a dent in solving the problem [12].

\subsection{Mobile Phones and Contribution to Greenhouse Gas Emissions}

The production of new mobile phones contributes to climate change by exhausting energy and processing materials, thereby releasing greenhouse gases into the atmosphere. The United Nations Environment Programme (UNEP) has estimated that the manufacturing of a single mobile phone produces about $60 \mathrm{~kg}$ of $\mathrm{CO}_{2} \mathrm{e}$ and using a mobile phone for a year produces about $122 \mathrm{~kg}$ of $\mathrm{CO}_{2} \mathrm{e}$. To put it in perspective, the $\mathrm{CO}_{2}$ emissions per subscriber per year for a typical $3 \mathrm{G}$ system are equivalent to the emissions from driving a car for $250-380 \mathrm{kms}$ or using 19 - 21 liters of gasoline. Researchers at McMaster University recently found that mobile phones with larger screens have a measurably worse carbon footprint than their smaller ancestors [13]. Similarly, a recent study on iPhones, confirmed that the production stage itself contributes to over 60 percent of greenhouse gas emissions generated in the product cycle [14]. Usage and maintenance contribute another 30 percent, while packaging, distribution, and disposal accounts for the remaining amount. Since a new iPhone is designed every two years, the entire process is a significant contributor to greenhouse gas emis- 
sions. Also, it has been found that newer iPhone versions are more carbon intensive than their older counterparts. For example, recent studies have concluded that the iPhone $6 \mathrm{~s}$ creates 57 percent more $\mathrm{CO}_{2}$ than the iPhone $4 \mathrm{~s}$.

\section{How to Deal with the Harmful Effects of Mobile Phones?}

Mobile phones have come to play a vital role in our lives especially the way we communicate with rest of the world. They have also offered great opportunities to millions living in poverty. Yet, the use of mobile phones comes at a huge cost to the society, whether it be in the form of health or environmental impacts-some known and some unknown.

When mobile phones are improperly recycled or end up in landfills, it ultimately causes negative effects to nearly every system in the human body. To stop this deadly trend, businesses and individuals need to recycle used mobile phones and other electronics to ensure their toxic e-waste does not end up in a landfill. Also, there should be proper legislation dealing with export of E-waste in the developed countries.

The radiation aspect of mobile phones is still an important area of research. Although inconclusive, it is an area we should keep a close eye on. The FCC has started providing information about the specific absorption rate (SAR) of cell phones produced and marketed within the last 1 to 2 years. The SAR corresponds to the relative amount of radiofrequency radiation absorbed by the head of a cell phone user. Consumers can access this information using the phone's FCC ID number, which is usually located on the case of the phone.

In terms of other harmful side effects, it is important to create awareness on about the potential harmfulness of mobile phone use among youth. Not only has mobile technology considerably reduced face-to-face communication (often bordering on isolation), but cyber bullying has also unfortunately increased since the inception of mobile devices. Parents, as well as teachers, should start to ration mobile phone usage amongst children and enforce "tech breaks". The media can play a major role in raising awareness about the negative consequences of mobile phone usage and offer helpful tips to tackle the consequences.

Furthermore, distracted driving is becoming a serious and growing threat to road safety. With more and more people owning mobile phones, this problem is likely to escalate globally in the years to come. While a number of countries have taken steps to legislate mobile phone use, to date, there is alack of research that examines the effectiveness of legislation in sustaining reduced levels of use of mobile phones, and not to mention even less evidence on the effects of these laws in reducing road traffic injuries or fatalities [15].

\section{Conclusion}

All in all, we are only starting to better understand the serious environmental harm caused by the production, usage, and disposal of mobile phones. While there are now some life cycle assessments of mobile technologies, we still need 
more research on how to salvage materials from mobile phone waste and how to reduce the negative environmental impacts of mobile production process. A good segue from that research will be to enact labelling schemes that help to identify greener mobile phones in the market in terms of their environmental and carbon footprint. More regulations may be needed to direct companies manufacturing mobile phones as well as users disposing of their mobile phones with increased frequency. This may call for new standards pertaining to mobile waste disposal as well as production. There's a need for mobile phone consumers to be educated on the potential environmental effects associated with improper mobile phone usage and disposal. More work is needed to improve the systematic collection of mobile phone use in traffic accidents to assess the extent of the problem in individual countries. This will allow prevention efforts to be effectively targeted. More research is also needed to better understand the impacts of different forms of mobile phone use such as sending or receiving text messages on driving behavior and crash risk in real-life settings. In conclusion, it is clear that an increase in awareness about the pros and cons of mobile phone production, distribution and usage is absolutely critical as mobile devices become ever ingrained in our society.

\section{Acknowledgements}

I would like to thank Professor Gurumurthy Ramachandran of the School of Public Health, Johns Hopkins University for his guidance on the topic and thoughtful comments and suggestions on an earlier version. Also, I would like to thank Rahul Mani of Brown University for his useful editorial comments and suggestions.

\section{Conflicts of Interest}

The author declares no conflicts of interest regarding the publication of this paper.

\section{References}

[1] Wostall, T. (2015) Mobile Phones Are the Greatest Poverty-Reducing Tech EVER and Possibly Africa's Only Real Source of Economic Growth. 23 Sep. 2015, The Register.

[2] Kumar, L., Shyam, N., Batra, A. and Saxena, M.R. (2017) Life Cycle Assessment (LCA) of Mobile Phones. International Journal of Current Research, 9, 5254252546. https://www.journalcra.com/article/life-cycle-assessment-lca-mobile-phones

[3] Babatunde, O.A., Eguma, C.A., Oyeledun, B.T., Igwilo, O.C., Awosanya, O.G. and Adegbenro, O. (2014) Mobile Phone Usage and Battery Disposal in Lagos, Nigeria. International Journal of Applied Psychology, 4, 147-154. https://pdfs.semanticscholar.org/6ac2/74749913e2ad9315b786fb579c25a1f30205.pdf

[4] https://e360.yale.edu/features/toxics_in_the_clean_rooms_are_samsung_workers_a t_risk 
[5] Velmurugan, M.S. (2016) Environmental Hazards and Health Risks Associated with the Use of Mobile Phones. Journal of Green Engineering, 5, 151-174. https://doi.org/10.13052/jge1904-4720.524

[6] https://www.e-cycle.com/cell-phone-toxins-and-the-harmful-effects-on-the-human -body-when-recycled-improperly

[7] Ahlbom, A., Green, A., Kheifets, L., et al. (2004) Epidemiology of Health Effects of Radiofrequency Exposure. Environmental Health Perspectives, 112, 1741-1754. https://doi.org/10.1289/ehp.7306

[8] The Interphone Study Group (2010) Brain Tumour Risk in Relation to Mobile Telephone Use: Results of the Interphone International Case-Control Study. International Journal of Epidemiology, 39, 675-694. https://doi.org/10.1093/ije/dyq079

[9] Aydin, D., Feychting, M., Schüz, J., et al. (2011) Mobile Phone Use and Brain Tumors in Children and Adolescents: A Multicenter Case-Control Study. Journal of the National Cancer Institute, 103, 1264-1276. https://doi.org/10.1093/jnci/djr244

[10] Thomee, S., Harenstam, A. and Hagsberg, M. (2011) Mobile Phone Use and Stress, Sleep Disturbances, and Symptoms of Depression among Young Adults-A Prospective Cohort Study. BMC Public Health, 11, 66.

https://doi.org/10.1186/1471-2458-11-66

[11] Babadi-Akashe, Z., Zamani, B.E., Abedini, Y., Akbari, H. and Hedayati, N. (2014) The Relationship between Mental Health and Addiction to Mobile Phones among University Students of Shahrekord, Iran. Addict Health, 6, 93-99.

[12] https://www.cmtelematics.com/company-news/telematics-data-shows-distracted-dr iving-occurring-more-frequently

[13] Belkkhir, L. and Elmelgi, A. (2018) Assessing ICT Global Emissions Footprint: Trends to 2040 \& Recommendations. Journal of Cleaner Production, 177, 448-463. https://doi.org/10.1016/j.jclepro.2017.12.239

[14] Nokia (2005) Integrated Product Policy Pilot Project Stage I Final Report: Life Cycle Environmental Issues of Mobile Phones. https://ec.europa.eu/environment/ipp/pdf/nokia_mobile_05_04.pdf

[15] World Health Organization. Mobile Phone Use: A Growing Problem of Driver Distraction.

http://www.who.int/violence_injury_prevention/publications/road_traffic/distracte d_driving/en/index.html 